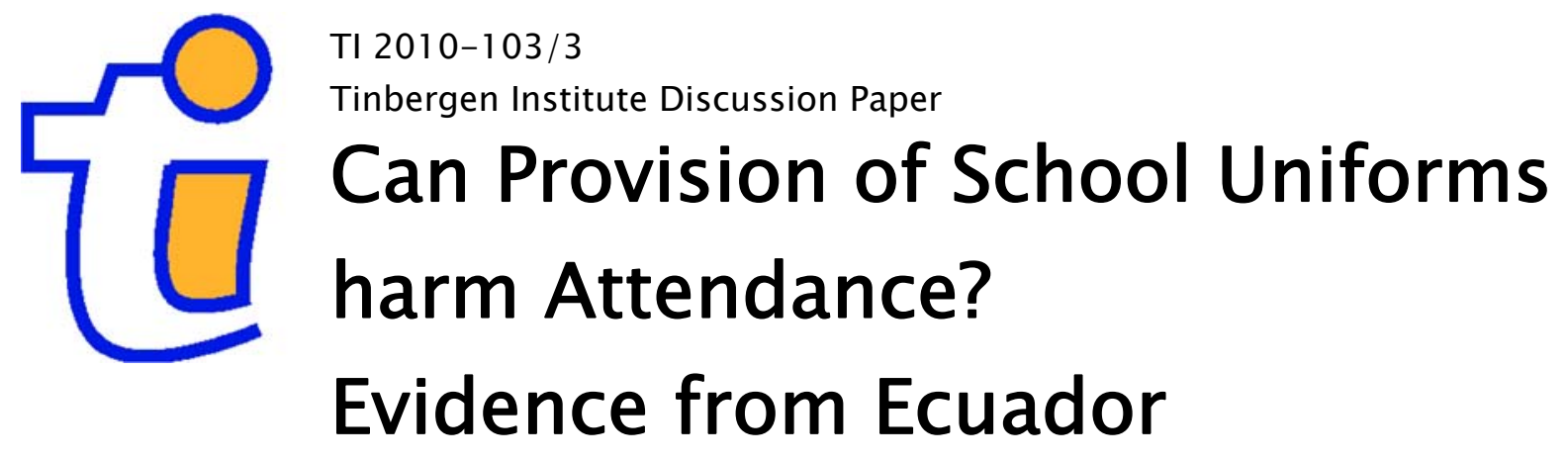

Diana Hidalgo 1,3,4

Mercedes Onofa ${ }^{2}$

Hessel Oosterbeek 1,3,4

Juan Ponce ${ }^{2}$

' Faculty of Economics and Business, University of Amsterdam;

2 FLASCO-Ecuador;

3 Tinbergen Institute;

${ }_{4}^{4}$ TIER. 


\section{Tinbergen Institute}

The Tinbergen Institute is the institute for economic research of the Erasmus Universiteit Rotterdam, Universiteit van Amsterdam, and Vrije Universiteit Amsterdam.

Tinbergen Institute Amsterdam

Roetersstraat 31

1018 WB Amsterdam

The Netherlands

Tel.: +31(0)205513500

Fax: $+31(0) 205513555$

Tinbergen Institute Rotterdam

Burg. Oudlaan 50

3062 PA Rotterdam

The Netherlands

Tel.: + $31(0) 104088900$

Fax: $+31(0) 104089031$

Most TI discussion papers can be downloaded at http://www.tinbergen.nl. 


\title{
Can provision of free school uniforms harm attendance? Evidence from Ecuador ${ }^{1}$
}

\author{
Diana Hidalgo Mercedes Onofa
}

Hessel Oosterbeek Juan Ponce

\footnotetext{
${ }^{1}$ This version: October 2010. Hidalgo and Oosterbeek are affiliated with the University of Amsterdam and TIER. Onofa and Ponce are affiliated with FLACSO-Ecuador. We gratefully acknowledge valuable comments from Adam Booij, Thomas Buser, Arnaud Chevalier, Monique de Haan, Dean Karlan, Noémi Péter, José Rosero and conference participants in Amsterdam.
} 


\begin{abstract}
To raise school attendance, many programs in developing countries eliminate or reduce private contributions to education. This paper documents an unintended negative effect of such programs. Using data from a randomized experiment that provides free uniforms to primary school children in Ecuador, we find that the intervention has a significantly negative impact on attendance. An explanation is that parents who pay for their children's uniforms (the control group) feel more committed to the school than parents who got the uniforms for free (the treated) and therefore encourage their children to attend school. Consistent with this sunk cost effect, we find that the impact is largest shortly after the purchase of the uniform, and during the end-of-year exam period when more is at stake.
\end{abstract}

JEL-codes: I22, I38, O15, H52

Keywords: Uniforms, school attendance, sunk-cost effect, Ecuador 


\section{Introduction}

Governments of developing countries and NGO's alike consider it a priority to increase school enrollment and attendance. The government of Ecuador is no exception. As financial constraints are regarded a barrier for children from poor families to go to school, the government eliminated school fees for children from poor families and provides free school meals and text books. Recently it also started to provide free school uniforms to children from poor families in rural areas with the plan to expand this program to poor urban areas. ${ }^{1}$

In this paper, we examine to what extent the provision of free school uniforms to children in primary schools contributes to an increase in their attendance. Free uniforms may affect attendance if children more often have clean clothes to wear to go to school, or if they have to spend less time earning money to cover the expenses of a uniform. For this study we took advantage of the further expansion of the program into poor urban areas in Ecuador. One hundred and one schools randomly chosen from a sample of 201 schools - were provided free uniforms one year ahead of the official schedule (in 2009 instead of 2010). Information about enrollment and about school and teacher characteristics was collected through a baseline survey in the beginning of the school year (in May 2009). In addition, we made three unannounced visits (in July, September and November) to the schools to register attendance of children enrolled in fifth and sixth grade.

It is important to notice that the unit of treatment in this experiment are schools. This implies that all children enrolled in a school that is assigned to the treatment group receive their school uniform for free. Since there was no public announcement of the assignment of schools to the treatment group (implying free uniforms), parents could not react to it by sending their child to a treated school instead of an untreated school. We therefore do not expect an impact of treatment on school enrollment, and our findings are consistent with that: enrollment is not affected by the provision of free uniforms. Because of this, we can examine the impact of free uniforms on attendance without worrying about contamination due to treated schools attracting additional - perhaps different - pupils.

Somewhat unexpectedly - at least for the Ecuadorian government -, we find

\footnotetext{
${ }^{1}$ Ecuador is among the countries where school uniforms are compulsory. Other countries where uniforms are compulsory or common include many countries from the Commonwealth, as well as Brazil, Cambodia, Chile, China, Honduras, Indonesia, Israel, Japan, Philippines, South Korea and Turkey. Arguments in favor of (compulsory) school uniforms include: (1) increasing students' safety, (2) increase student learning and positive attitudes towards school, (3) decreased behavior problems by increased attendance rates, lowering suspension rates and decreasing substance use, and (4) increased self-esteem (Brunsma and Rockquemore, 1998).
} 
that the provision of free uniforms reduces attendance. Averaged over the three unannounced visits, attendance is 3.4 percentage points lower in the schools that received the free uniforms, this should be compared to baseline attendance amongst controls of 92 percent. This implies an almost 50\% increase in absenteeism. Our preferred explanation for this finding is that parents who pay for their children's school uniforms (those in the control group) feel more committed to the school than parents who got the uniforms for free (the treated) and therefore do not allow their children to miss classes too easily. Consistent with this sunk cost explanation, we find that the impact on attendance is larger the first time that we measure it than the second time. This first time is closer to the actual purchase of the uniforms by parents in the control group. The negative impact is again larger during the last visit which is around the end-of-year exam period. Results on these exams are important for final grades and for the decision to advance pupils a grade. The exams may function as a reminder to parents in the control group of the cost they incurred. During the exams these parents may therefore encourage their children to attend in order to make their purchase of the uniform worthwhile.

Our findings stand in contrast with the results reported by Evans et al. (2008), who evaluate the impact of a very similar intervention in which free uniforms were provided to primary school children in western Kenya. That program selected 12 schools for the intervention, and within schools 612 children were randomized into treatment and 693 others to the control group. The results from this study indicate that receiving a uniform increased attendance by 7 percentage points, where baseline attendance is 82 percent. Effects are larger for girls (than for boys), for younger children (than for older children), and for children that did not have a uniform at baseline. The main reason why Evans et al.'s finding does not travel, is probably the difference in absolute poverty between Kenya and Ecuador. While the free uniforms in Kenya are actually lifting a binding credit constraint, the free uniforms in Ecuador are merely replacing the uniforms parents of targeted pupils would have bought anyhow. ${ }^{2}$

Two recent studies deal with the sunk cost effect in the context of developing countries. $^{3}$ Ashraf et al. (2010) conducted an experiment in a door-to-door sale of a water purification product to about 1,000 households in Zambia. To disentangle selection effects from sunk cost effects, the authors used a two-stage pricing design.

\footnotetext{
${ }^{2}$ The difference in results can perhaps also be attributed partially to different levels of randomization: across schools in Ecuador versus within schools in Kenya.

${ }^{3}$ The classical empirical study reporting evidence of a sunk cost effect is Arkes and Blumer (1985), who present evidence that customers who had initially paid more for a season subscription to a theater series attended more plays during the next 6 months.
} 
In the first stage, participating households were offered the product for a one-time only, randomly chosen offer price, which was above zero and at or below the prevailing retail price. In the second stage, households that agreed to purchase received an unanticipated, randomly chosen discount. Two weeks later data were collected concerning usage of the product. The study finds no evidence that households paying a higher transaction price are more likely to use the product, some of the point estimates even suggest the opposite effect. If, however, paying something is compared to paying nothing, point estimates are consistent with the sunk cost effect, although not significantly so. This latter result is the relevant comparison for our paper, since we also compare paying something to paying nothing. Cohen and Dupas (2010) use a very similar two-stage design as Ashraf et al. to estimate the impact of the price paid on the usage of antimalarial insecticide-treated bed nets that were offered by prenatal clinics to pregnant women in Kenya. Cohen and Dupas also fail to find a significant effect of the price on usage. The point estimates are negative, in this case even when paying something is compared to paying nothing. An explanation for the different findings regarding the sunk cost effect, is a difference in prices between the products. While the water purification product and the bed net cost less than 1 US\$, school uniforms in Ecuador cost close to 25 US\$. Obviously, the sunk cost effect is more likely to play a role if the costs that have been sunk are large.

The rest of the paper is organized as follows. The next section describes the context of the education system in Ecuador and provides further details of the free uniforms program. Section 3 describes the experimental design and the data. Section 4 presents and discusses the main results. The final section summarizes and concludes.

\section{Context and program}

Ecuador is a low-middle income country with a large share of poor families and high inequality. Compulsory schooling in Ecuador starts at the age of 5 and ends at the age of 14. This covers one year of pre-school, six years of primary school and three years of basic secondary school. Enrollment at the primary level is almost universal (over 95\%), but drops sharply at the transition from primary to secondary school. This drop is mainly concentrated among children from poor families. Official statistics on school attendance are not available. Based on the data used in this paper, absenteeism is close to 10 percent. Typically, school-aged girls who do not go to school help their mothers with domestic work, whereas boys usually help with farm work or work as street vendors. 
Wearing a school uniform is compulsory in Ecuador and children can in principle not attend school without one. Normally, parents buy uniforms in specialized shops before the beginning of the school year. Each city or town has some of these shops, which make uniforms for several schools. In some cases, parents' associations have an agreement with artisans to make uniforms. Schools do not play any role in this process. Extremely poor parents may instead of buying a uniform, buy the raw materials and make the uniforms themselves.

In 2007 the government of Ecuador launched the free uniforms program. The program has two distinct objectives. It intends to increase school attendance among children in poor areas, and it aims to improve local economic conditions by contracting small and medium-sized local artisans for the production of the uniforms. In the first phase only children enrolled in public schools in rural areas were served. In 2008 the government decided to expand the program to public schools in poor urban areas by 2010 .

Since uniforms are compulsory, exposure to the free uniforms program implies that parents do not have to pay for a uniform on which they would otherwise have spend between 20 and 25 US\$. We calculated this amount on the basis of the 2006 Survey of Life Conditions in Ecuador. This survey asked respondents for each child in the family whether money was spend on a school uniform during the last 12 months, and if so, how much. We restricted the sample to children 10-12 years old (the age range for which we have attendance data), living in the provinces that are included in our experiment and from families in the lowest two quintiles of the wealth distribution. In this sample of 625 observations, money was spend on a uniform during the last 12 months for 81 percent of the children, with average expenditures of 24 US $\$$. This fraction and average amount are somewhat higher for boys than for girls: $83 \%$ versus $80 \%$, and 25.9 US $\$$ versus 21.8 US $\$$. The first difference is not significantly different from zero ( $\mathrm{p}$-value $=0.267)$, the second is $(\mathrm{p}$-value $=0.015)$. The amount of 24 US $\$$ can be compared to average monthly household expenditures in the two lowest quintiles of the wealth distribution of around 100 US $\$$ (cf. Oosterbeek et al., 2008).

Artisans could only be contracted for the government's free uniform program if they satisfied certain quality standards, so that the free uniforms were of at least the same quality as regular uniforms. This excludes that a negative effect of free uniforms on attendance is due to inferior quality of the free uniforms. 


\section{Design and data}

The government of Ecuador invited us to evaluate the impact of the provision of free uniforms on school attendance. Given the planned expansion of the program, we proposed to provide the free uniforms to some schools one year ahead of the official schedule, in 2009 instead of 2010. Two hundred and one schools in five provinces were selected to participate in the experiment. We randomly assigned half of these schools to the treatment of the provision of free school uniforms one year ahead of the official schedule. The other half was assigned to the control group and was thus supposed not to receive free school uniforms in 2009.

Due to problems with the production of the uniforms (artisans were contracted too late because of administrative issues), we had to exclude two provinces from the analysis. In these provinces just two out of 52 schools received free uniforms. Since randomization was stratified by province, we can drop the observations from these two provinces without harming the experimental design. All the analyses in this paper will therefore be based on observations for the three remaining provinces: Guayas, Los Ríos and Manabí. ${ }^{4}$ While also in the remaining provinces there is some degree of contamination, assigned treatment status and actual treatment status are highly correlated, implying that we can use assigned treatment status as an instrument for actual treatment status. ${ }^{5}$

At the end of the school year $2007 / 8$, schools in the treatment group were informed that next school year they would receive free uniforms. At this time, parents were informed that they did not have to buy a uniform for the coming year. Treated schools had to submit a list with names, gender, grades and uniform size of their pupils, to the Ministry of Education. The ministry contracted local artisans to make the uniforms before the start of the new school year. The uniforms were handed out during the first days of the new school year.

The data that we use in this study were collected at the school level through a baseline survey in the beginning of the school year (in May 2009). In addition, school attendance was measured for all pupils in grades five and six through three unannounced visits (in July, September and November). In grades five and six, pupils are normally age 10 to 12 . Collection of attendance data was limited to pupils in just two grades for cost considerations. Grades five and six were chosen because it was assumed that at this age pupils' attendance is more sensitive to the

\footnotetext{
${ }^{4}$ Ecuador has 24 provinces, many of them sparsely populated. The three provinces included in this study are located in the coastal part of the country (as opposed to the mountains or the jungle). Together the three provinces have a population of almost 5 million people; the total population of Ecuador amounts to 13 million people.

${ }^{5}$ Further details about the first stage results are given in Subsection 4.1.
} 
provision of free uniforms. Moreover, pupils in fifth and sixth grade are unlikely to change schools in response to the provision of free uniforms, thereby reducing the possibility that our estimates are contaminated by selection effects.

The school level questionnaire contains information about school infrastructure, the number of teachers, availability of books, computer labs, and other school inputs. The school questionnaire was addressed to the school principals. A special section in the questionnaire about the number of students enrolled in every grade during the current and past year is used to construct enrollment variables. Teachers were interviewed separately and from that information we construct the share of female teachers and the average age and experience of teachers in the school. These variables will be used as control variables.

Table 1 shows descriptive statistics at the school level, separately for schools assigned to the treatment group and for schools assigned to the control group. The final column in this table shows p-values that test for differences in means between treated and controls. None of the p-values is below 0.10 , indicating that the randomization worked properly. The descriptives also show that the average school is rather small, with only four to five teachers and around 140 pupils. Eighty percent of the primary school teachers in our sample of schools is female. The average level of education is between secondary school (level 4) and professional college (level 5 ), and average experience is close to 20 years. Although most schools own their premises, the scores on the indexes for infrastructure and pedagogical equipment are rather low. This is probably the clearest indication that the schools included in this study all belong to the poor segment of the country.

Besides selection effects - which we address in Subsection 4.2, three other factors may potentially confound our results. First, parents in control schools may anticipate the implementation of the free uniforms program in the year following the experiment, and may therefore postpone the purchase of a uniform. Second, some schools may not be so strict with respect to the requirement to wear a uniform and may allow their pupils to attend school without one. Finally, receiving a free uniform may generate an income effect. The first two factors bias the results against finding a sunk cost effect since in both cases parents in the control group are less pressed to sink a cost by purchasing a uniform. Also an income effect from free uniform provision biases the results against a sunk cost effect unless attending school is an inferior good. This would be hard to reconcile with the strong positive correlation between parental income and children's school participation found in many studies. ${ }^{6}$

\footnotetext{
${ }^{6}$ One might also worry that recipients of free uniforms resell their uniforms. Given that the colors of uniforms are school specific and all schoolmates of pupils that received free uniforms also received free uniforms, this seems an unlikely scenario.
} 
Table 1. Balancing of treatment and control schools

\begin{tabular}{lccccc}
\hline \multirow{2}{*}{ Variable } & \multicolumn{3}{c}{ Controls } & \multicolumn{2}{c}{ Treated } \\
\cline { 2 - 5 } & Mean & SD & Mean & SD & p-value \\
\hline Infrastructure index (0-7) & 2.522 & $(1.378)$ & 2.763 & $(1.896)$ & 0.379 \\
Pedagogical equipment index (0-4) & 1.145 & $(0.944)$ & 1.158 & $(1.033)$ & 0.937 \\
At least one class per grade & 0.435 & $(0.499)$ & 0.474 & $(0.503)$ & 0.641 \\
School owns building & 0.899 & $(0.304)$ & 0.921 & $(0.271)$ & 0.640 \\
Share of female teachers & 0.817 & $(0.256)$ & 0.793 & $(0.291)$ & 0.593 \\
Number of teachers & 4.692 & $(2.890)$ & 5.125 & $(4.217)$ & 0.469 \\
Mean education level teachers & 4.255 & $(0.563)$ & 4.249 & $(0.767)$ & 0.956 \\
Mean experience teachers (yrs) & 19.20 & $(8.37)$ & 18.42 & $(8.32)$ & 0.574 \\
School size pre-treatment (\# pupils) & 138.2 & $(109.2)$ & 146.8 & $(133.6)$ & 0.671 \\
\hline$N$ & 69 & \multicolumn{5}{c}{76} \\
Note: The infrastructure index is the sum of dummies for presence of: boarding for teachers, \\
potable water, electricity, sewage, bathroom, telephone, a teachers' room, a health clinic, a play- \\
ground and Internet access. The pedagogical equipment index is the sum of presence of special \\
instructions room, science lab, computer lab, classrooms in good condition and library.
\end{tabular}

\section{Results}

\subsection{The relation between assigned treatment on actual treatment}

Not all schools that were supposed to receive free uniforms actually received them. As mentioned above the schools from two provinces were dropped altogether as (almost) no school in these provinces received free uniforms. In the other three provinces actual treatment is highly but not perfectly correlated with assigned treatment. In case of such contamination in a randomized experiment, the standard practice is to use the assigned treatment as an instrumental variable for actual treatment. This is also the approach we follow here.

After dropping the schools from the two provinces where no uniforms were provided, we are left with 149 schools. Two of these schools turn out to specialize in adult education and two schools have missing data on school attendance. As a result we end up with 145 schools. Table 2 shows how these schools are divided over assigned and actual treatment status. Twenty-four schools have an actual treatment status that differs from their assigned treatment. ${ }^{7}$ For the other 121 schools the

\footnotetext{
${ }^{7}$ The 14 schools that should have received free uniforms but did not, were informed before the school year started that the artisans that were contracted to produce their uniforms, could not deliver. The 10 schools that received uniforms while they should not, were mainly smaller schools that combine pre-school and primary school. Free uniforms are provided to all pre-school children in Ecuador. Some small schools that combine pre-school and primary school and that were assigned to the control group, were confused about the fact that the uniforms were only free for their pre-school pupils.
} 
Table 2. Numbers of schools (and pupils) by assigned versus actual treatment status

\begin{tabular}{lcccc}
\hline & & \multicolumn{3}{c}{ Assigned treatment } \\
\cline { 3 - 5 } & & $Z=0$ & $Z=1$ & Total \\
\cline { 3 - 5 } Actual & $T=0$ & 59 & 14 & 73 \\
treatment & & $(2569)$ & $(841)$ & $(3410)$ \\
& $T=1$ & 10 & 62 & 72 \\
& & $(213)$ & $(2530)$ & $(2743)$ \\
\cline { 3 - 4 } & Total & 69 & 76 & 145 \\
& & $(2782)$ & $(3371)$ & $(6153)$
\end{tabular}

Note: Cells report number of schools and in parentheses the number of pupils. $Z$ refers to assigned treatment, $T$ refers to actual treatment.

assigned treatment status corresponds to the actual treatment status. In these 145 schools we have attendance records of 6,153 pupils in fifth and sixth grade, giving an average number of observed pupils per school of around 42. The schools that were assigned to treatment but did not receive it, have a larger number of fifth and sixth graders, while the schools that were assigned to control but did receive the free uniforms have smaller numbers of fifth and sixth graders on average.

Table 3 shows the estimates of regressions of actual treatment status on assigned treatment status. Regressions are presented both at the pupil level (with standard errors clustered at the school level) and at the school level, and from specifications without and with control variables. All coefficients are around 0.7 and are highly significant. Inclusion of control variables has almost no effect on the estimated impacts.

Contamination of treated and controls potentially limits the generalizability of our estimates. Where an uncontaminated randomized experiment would in principle recover the average treatment effect, instrumental variable methods estimate a local average treatment effect (Imbens and Angrist, 1994). This latter effect is identified from the observations that change treatment status because of the result of the randomization. While we cannot observe who the compliers are, it is possible to characterize them by estimating the mean values of their observed characteristics using Abadie's kappa weighting scheme (see Abadie, 2003). Table 4 reports the estimated means for the compliers and for comparison also the means for all schools. This shows that the estimated mean characteristics for the complying schools are very similar to those of all schools. This establishes that compliers are - at least in terms of observables - not a specific subgroup. 
Table 3. The impact of assigned treatment on actual treatment

\begin{tabular}{lcccc}
\hline & \multicolumn{2}{c}{ Pupil level } & \multicolumn{2}{c}{ School level } \\
\cline { 2 - 5 } Assigned treatment & $0.674^{* * *}$ & $0.709^{* * *}$ & $0.671^{* * *}$ & $0.669^{* * *}$ \\
& $(0.081)$ & $(0.065)$ & $(0.062)$ & $(0.062)$ \\
F-statistic & 69.3 & 118.7 & 117.6 & 115.8 \\
$N$ & 6153 & 6153 & 145 & 145 \\
\hline Controls & no & yes & no & yes
\end{tabular}

Note: Controls at the school level include indicators for infrastructure and pedagogical equipment, a dummy for the school having at least one class per grade, a dummy for the school owning the building, percentage female teachers, number of teachers, average level of teachers' education, teachers' experience in the teaching profession and dummies for province. Additional controls at the pupil level are dummies for pupils' sex and grade, pupils' age, class-size, share of girls in the class. At school level, robust standard errors in parentheses. At pupil level, standard errors clustered at school level in parentheses. ${ }^{* * *}$ indicates significance at the $1 \%$-level.

Table 4. Comparing complying schools to all schools

\begin{tabular}{lccc}
\hline & Compliers & \multicolumn{2}{c}{ All } \\
Variable & Mean & Mean & SD \\
\hline Infrastructure index (0-7) & 2.486 & 2.648 & 1.669 \\
Pedagogical index (0-4) & 1.132 & 1.152 & 0.988 \\
At least one class per grade & 0.563 & 0.455 & 0.500 \\
School owns building & 0.881 & 0.910 & 0.287 \\
Share of female teachers & 0.816 & 0.804 & 0.274 \\
Number of teachers & 4.942 & 4.919 & 3.641 \\
Mean education level teachers & 4.324 & 4.252 & 0.675 \\
Mean experience teachers (yrs) & 19.44 & 18.79 & 8.323 \\
School size pre-treatment (\# pupils) & 140.9 & 142.7 & 122.2 \\
$N$ & & 145 & \\
\hline
\end{tabular}

Note: The infrastructure index is the sum of dummies for presence of: boarding for teachers, potable water, electricity, sewage, bathroom, telephone, a teachers' room, a health clinic, a playground and Internet access. The pedagogical equipment index is the sum of presence of special instructions room, science lab, computer lab, classrooms in good condition and library. 


\subsection{The impact of free uniforms on school enrollment}

In the next subsection we estimate the impact of free uniform provision on school attendance of pupils in fifth and sixth grade. To interpret these estimates as the impact of the provision of free school uniforms on attendance, the intervention should not have an impact on school enrollment. Otherwise the estimated impact might reflect a change in the student composition of treated schools rather than a direct impact of free uniforms on attendance. This would for instance be the case if the provision of free uniforms attracts marginal students - students whose school choice is determined by the provision of free uniforms instead of school quality. Such students may not only be attracted by the free uniforms but may also be less inclined to attend school. ${ }^{8}$ It would also be the case if some pupils who would otherwise have dropped out, decide to stay on because of the free uniforms.

Since the provision of free uniforms to treatment schools was not publicly announced, it is unlikely that treated schools attract pupils from other schools. It is especially unlikely that pupils switch schools in response to free uniforms when they are already in fifth or sixth grade. Because enrollment in primary school is almost universal, reduced dropping out in response to the free uniforms provision seems also unlikely.

Nevertheless, to examine these issues, we collected data on school enrollment. In the baseline questionnaire, principals were asked to report the numbers of enrolled pupils in their school in the current year (2009) and the previous (2008), broken down by gender and grade level.

In Table 5 we present IV estimates of the impact of the provision of free uniforms on grade and gender specific enrollment levels. In all specifications enrollment in the year of the experiment is regressed on enrollment in the previous year and on a variable indicating the provision of free school uniforms, where this indicator is instrumented by the assigned treatment status. We present results from specifications with and without further control variables. In the first two columns lagged enrollment is measured as the number of pupils in the same school of the same sex in the same grade in the previous year. This specification is motivated by the possible attraction to treated schools of pupils from other schools. In the last two columns lagged enrollment is measured as the number of pupils in the same school of the same sex of the same cohort in the previous year. This specification is motivated by the possible reduction of dropping out in treated schools.

The results in Table 5 show no sign of any impact on enrollment. Of the 16

\footnotetext{
${ }^{8}$ This is for instance what Ashraf et al. (2010) find. Households who want to buy the water purification product at a higher offer price are more likely to use it.
} 
Table 5. Estimates of the impact of free uniforms on school enrollment by grade and gender

\begin{tabular}{lcccc}
\hline Grade/gender & $(1)$ & $(2)$ & $(3)$ & $(4)$ \\
\hline Fifth grade boys & 1.831 & 1.319 & 0.017 & -0.027 \\
& $(1.463)$ & $(1.282)$ & $(0.844)$ & $(0.833)$ \\
Fifth grade girls & 0.139 & -0.342 & 0.593 & 0.334 \\
& $(1.203)$ & $(1.129)$ & $(0.788)$ & $(0.749)$ \\
Sixth grade boys & -0.633 & -0.434 & 1.020 & 0.758 \\
& $(1.343)$ & $(1.186)$ & $(0.816)$ & $(0.771)$ \\
Sixth grade girls & 0.285 & -0.188 & 0.729 & 0.646 \\
& $(1.282)$ & $(1.182)$ & $(0.805)$ & $(0.786)$ \\
\hline Control lagged enrollment same grade & yes & yes & no & no \\
Control lagged enrollment same cohort & no & no & yes & yes \\
Further controls & no & yes & no & yes \\
\hline
\end{tabular}

Note: All regressions include controls for lagged enrollment and province dummies. Further controls include indicators for infrastructure and pedagogical equipment, a dummy for the school having at least one class per grade, a dummy for the school owning the building, percentage female teachers, number of teachers, average level of teachers' education, teachers' experience in the teaching profession and dummies for province. Number of observations equals 145 schools.

estimates presented in the table none is significantly different from zero. We take this as evidence that the provision of free uniforms did not have any impact on school enrollment and thus that our estimates of the effect of free uniforms on attendance are not biased by changes in composition.

\subsection{The impact of free uniforms on school attendance}

Attendance was measured at an individual level for all pupils enrolled in fifth and sixth grade through three unannounced visits. These visits took place in July, September and November. The school year runs from April to December, so that July is relatively early in the school year. The base attendance rate among pupils in schools assigned to the control group is 0.93 during the first visit, 0.90 during the second visit, and 0.93 during the third visit. This gives an overall average base attendance rate of 0.92 among the pupils in control group schools. As the bottom rows of Table 6 show, base attendance rates are fairly similar for boys and girls, and for fifth and sixth graders. ${ }^{9}$

Table 6 reports estimates of the impact of the provision of free school uniforms on attendance. As dependent variables, we look at attendance during the three

\footnotetext{
${ }^{9}$ Using data from pupils in control schools, a regression of average attendance on pupil's sex allowing for clustering at school level gives a p-value of 0.279. A similar regression for grade level returns a p-value of 0.093 .
} 
visits separately and at attendance averaged over the three visits. ${ }^{10}$ We estimated specifications with and without control variables, and with and without interaction terms between provision of free uniforms and pupils' sex and grade. All estimates come from IV-regressions in which assigned treatment status is the instrument for free uniforms, and assigned treatment times a dummy for girl (or a dummy for sixth grade) is the instrument for the interaction term of free uniform and pupil's sex (grade).

All estimates from the specification without interactions (in the first row) have a negative sign, and six out of eight estimates are significantly different from zero. Only for attendance measured in September, estimates are not significantly different from zero. Pupils in schools where uniforms were provided for free are less likely to attend schools than pupils in schools where parents had to buy the school uniforms of their children. The size of the impact is around 4 percentage points. Relative to a base attendance rate of 0.92 , this is quite substantial. It implies that absenteeism increases by almost $50 \%$.

The next two panels in Table 6 present results from specifications with interaction terms. The results in the middle panel indicate that the negative impact of free uniforms on attendance is somewhat larger for boys than for girls, but the difference is only significant in November. The results in the bottom panel of the table show that the impact of free uniforms does not differ across grades.

The negative impact of the provision of free uniforms on attendance is surprising given the program's goal to increase attendance and given the previous finding for Kenya reported by Evans et al. (2008). Our preferred explanation for this unexpected finding is that private contributions for children's education positively affect parents' commitment. In the Ecuadorian context, the default is that parents purchase their children's school uniform. Hence parents are used to buying school uniforms and all children enrolled in a school will have one. The key difference between treated and controls is then that parents of children enrolled in control schools paid for the uniforms themselves whereas the parents of children enrolled in treated schools did not. To the extent that parents are prone to the sunk cost fallacy ("bygones are no bygones"), the purchase of a school uniform may stimulate them to send their children to school. In contrast, in the Kenyan context, the provision of free uniforms presumably lifts a binding credit constraint.

The fact that the intervention has a larger impact on attendance during the first visit than on attendance during the second visit is consistent with this sunk cost

\footnotetext{
${ }^{10}$ Most pupils who are absent, are only absent at one of the three visits. $78 \%$ is never absent, $19 \%$ is absent once, $3 \%$ twice, and less than $1 \%$ all three times.
} 


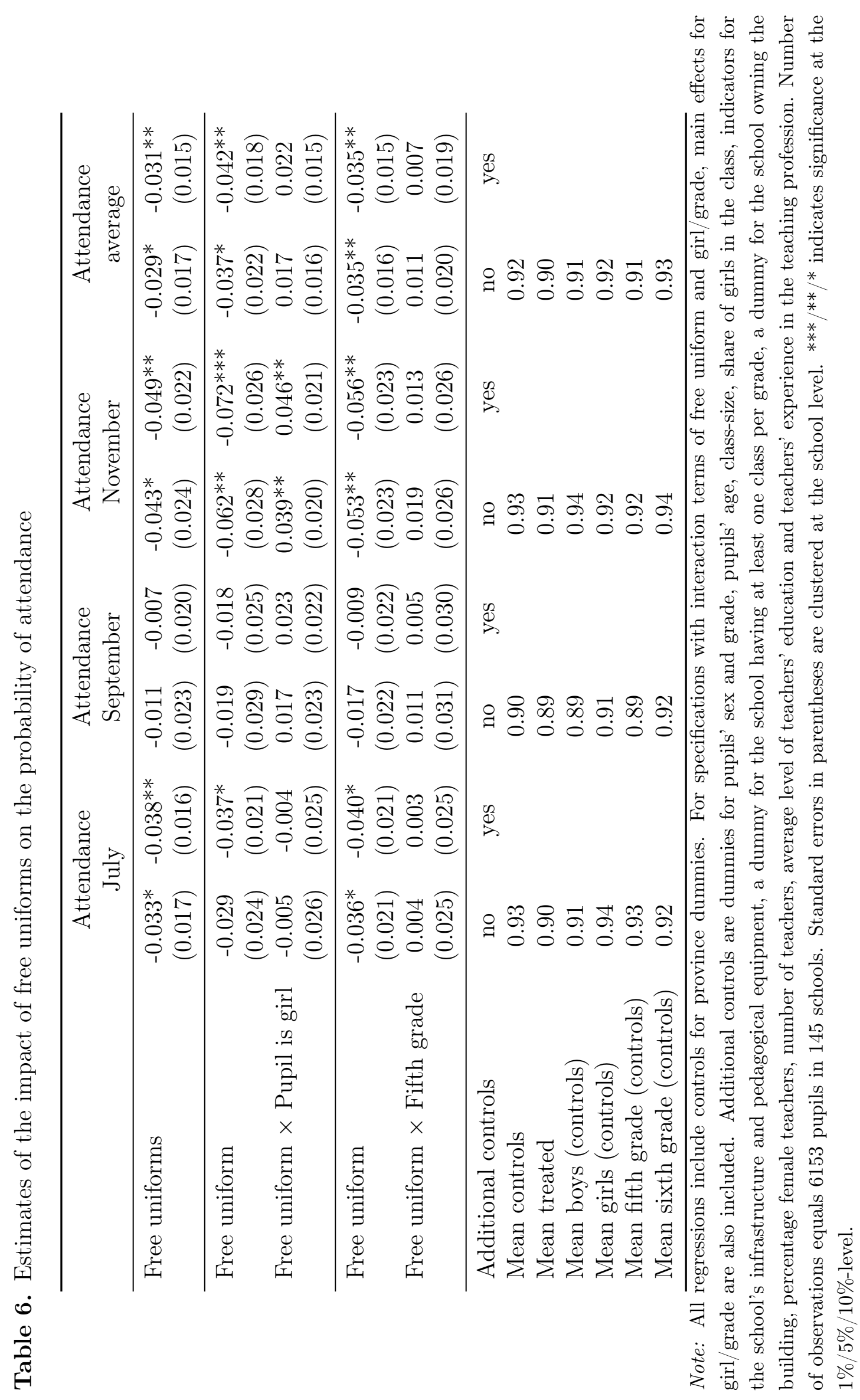


effect explanation. The first visit occurs in July, three months after most parents in the control group purchased the uniforms, whereas the second visit occurs two months later. It might be that during the time that elapsed between the first and the second visit, parents in the control group accepted the cost of their purchase is sunk. $^{11}$ The fact that the intervention has an even larger negative impact at the third visit may seem inconsistent with this. This is not the case, however, if parents' responsiveness varies with what is at stake. The last visit takes place in November. In Ecuador's coastal provinces this is towards the end of the school year, which is the period in which end-of-year exams are held and in which it is decided whether pupils are advanced a grade or not. In this period, parents in the control group may be reminded of their purchase earlier in the year, and they may stimulate their child to make this investment worthwhile. ${ }^{12}$

The somewhat larger negative impact of free uniforms on boys' attendance than on girls' attendance is consistent with the sunk cost explanation if parents spend more on uniforms for boys than on uniforms for girls. In Section 2 we reported results from the 2006 Survey of Life Conditions in Ecuador that show that this is indeed the case. Parents spend on average 25.9 US $\$$ on a uniform for a boy and $21.8 \mathrm{US} \$$ on a uniform for a girl, and this difference is statistically significant ( $\mathrm{p}$-value $=0.015$ ).

\section{Conclusions}

This paper evaluates the impact of the provision of free school uniforms on school attendance in Ecuador. In contrast to a previous study for Kenya that finds a positive impact of free uniforms on attendance, we find a significantly negative effect on attendance in Ecuador. While the programs in both countries are targeted at poor households, poor people in Ecuador are less poor than poor people in Kenya. This means that in Ecuador, everyone enrolling in school owns a uniform. The essential difference between treated and controls is then that parents of children enrolled in control schools paid for the uniforms themselves whereas the parents of children enrolled in treated schools did not.

An explanation for our finding is then that parents who pay for their children's school uniforms (those in the control group) feel more committed to the school than

\footnotetext{
${ }^{11}$ We notice, however, that the difference in impact between July and September is not significant at the 10\%-level. This was tested in a pooled specification with full interactions between controls and months. This also shows that the difference between September and November is significant at the $10 \%$-level.

${ }^{12}$ Ecuador is located on the equator and the coastal provinces do not have changing seasons. Hence, it is not the case that in November parents in the control group have to buy new clothing because the season changed.
} 
parents who got the uniforms for free (the treated) and therefore do not allow their children to miss classes too easily. Consistent with this sunk cost effect explanation, we find that the impact on attendance is larger shortly after the purchase of the uniform and during the exam period when more is at stake.

It is worthwhile to notice that the design of the experiment only allows us to assess the impact of a free uniforms program in the first year of its introduction. This is probably underestimating the impact of a free uniforms program some years after its introduction. The reason is that parents in the treatment group of the experiment may still be primed with the idea that education is worthwhile because they have been spending money on uniforms in previous years.

Ashraf et al. (2010) and Cohen and Dupas (2010) find no evidence of a sunk cost effect in the usage of health-related products in Sub-Saharan Africa. Apart from differences between health and education, an explanation for this difference may be the absolute costs of the products. The highest price paid for the water purification product in Ashraf et al.'s experiment equals US\$ 0.25 , which is about $0.1 \%$ of the monthly income of households in the target group. The highest price paid for a bed net in the study of Cohen and Dupas amounts to US\$ 0.60, which is around $0.3 \%$ of monthly income of households in the target group. These amounts are substantially below the US\$24 that Ecuadorian parents spend on a school uniform.

Obviously we should not jump to conclusions on the basis of the results from one experiment. Our result points, however, to a potentially important mechanism that so far has not received much attention. Private contributions to education may serve as a commitment device for parents to encourage their children to attend school.

\section{References}

Abadie, A. (2003). Semiparametric instrumental variable estimation of treatment models. Journal of Econometrics, 113:231-263.

Arkes, H. R. and Blumer, C. (1985). The psychology of sunk cost. Organizational Behavior and Human Decision Processes, 35:124-140.

Ashraf, N., Berry, J., and Shapiro, J. M. (2010). Can higher prices stimulate product use? Evidence from a field experiment in Zambia. American Economic Review, 100:forthcoming.

Brunsma, D. and Rockquemore, K. (1998). Effects of student uniforms in attendance, behavior problems, substance use, and academic achievement. Journal of Educational Research, 92:53-62. 
Cohen, J. and Dupas, P. (2010). Free distribution or cost-sharing? Evidence from a randomized malaria prevention experiment. Quarterly Journal of Economics, $125: 1-45$.

Evans, D., Kremer, M., and Ngatia, M. (2008). The impact of distributing schools uniforms on children's education in Kenya. Working paper.

Imbens, G. W. and Angrist, J. D. (1994). Identification and estimation of local average treatment effects. Econometrica, 62(2):467-475.

Oosterbeek, H., Ponce, J., and Schady, N. (2008). The impact of cash transfers on school enrollment: Evidence from Ecuador. Tinbergen Institute Discussion Paper. 